\title{
Reducing children's exposure to environmental tobacco smoke in homes: issues and strategies
}

\author{
Mary Jane Ashley, Roberta Ferrence
}

\begin{abstract}
It is now well established that children's exposure to environmental tobacco smoke (ETS) results in substantial public health and economic impacts. Children are more likely than adults to suffer health effects from ETS exposure, and the home is the most important site of such exposure.

Although the responsibility and authority of the community and health professionals to protect children from harm are entrenched in North American society, social, economic, legal, and political factors contribute to a lower level of support for ETS control measures in homes compared with workplaces and public places. It is now clear that ETS control in home environments must be a priority on the public health agenda. Programme and policy options and strategies for ETS control in home environments are outlined. We conclude that the current research base is inadequate to fully support programme and policy development in this area and priorities for research are identified.
\end{abstract}

(Tobacco Control 1998;7:61-65)

Keywords: environmental tobacco smoke, homes, children

Programmes and policies to reduce exposure to environmental tobacco smoke (ETS) in public places and workplaces have been widely implemented in North America. ${ }^{12}$ Much less attention has been directed to minimising ETS exposure in home environments, in particular, the exposure of children. Exploring the feasibility of programme and policy options for ETS control in homes must now be a public health priority. Although the rationale for such control is strong, various social, economic, legal, and political issues must be addressed. The research base for programme and policy development must also be strengthened.

\section{Rationale for addressing ETS in home environments}

The 1993 report of the Environmental Protection Agency (EPA) ${ }^{3}$ in the United States documented the causal association between ETS and important health effects in children. Several dozen studies published since then support its conclusions. Most recently, they have been further substantiated, refined, and extended by the comprehensive report of the California Environmental Protection Agency. ${ }^{4}$ It is now clear that ETS exposure is a cause of lower respiratory tract infections in children, such as bronchitis and pneumonia, and of fluid in the middle ear, symptoms of upper respiratory tract irritation, and a small but significant reduction in lung function. Further, ETS is a cause of new cases of asthma, additional episodes of asthma, and increased severity of asthmatic symptoms. As documented in the EPA and California reports, and also, in a recent comprehensive meta-analysis, ${ }^{5}$ the public health impact of children's exposure to ETS is substantial. In addition, it is clear that the economic impact is far from trivial. $^{67}$

Young children are especially vulnerable to ETS exposure. Compared with adults, they have higher relative ventilation rates leading to higher internal exposures to ETS, as measured by urinary cotinine, for the same level of external exposure. ${ }^{8}$ Infants and very young children cannot complain; older children who are bothered by ETS may not complain, or may be ignored or reprimanded when they do. Further, children often cannot remove themselves from exposure and, therefore, are dependent on other measures for protection.

The responsibility and authority of the community, professionals, and the state to protect children from harm are firmly entrenched in North American society. Community attitudes support the nurturing and protection of children, and various laws have been enacted to this end. Although the lack of regulation of children's exposure to ETS in homes is not consistent with some other community efforts to protect children, there are reasons for this inconsistency. Until the past decade, ETS was not known to be more than an irritant. Even today, many people are unaware of its health hazards. ${ }^{9}$ Others may believe that effective protection can be achieved with simple measures, such as opening a window, smoking in another room, or using an air purifier, ${ }^{10}$ although none of these measures substantially reduce exposure. ${ }^{11} 12$

Children, especially those of preschool age, are likely to spend much of their time at home. National surveys indicate that $37 \%$ to $39 \%$ of Canadians live in a home where smoking occurs regularly, ${ }^{13}$ (Health Canada, unpublished tabulations), and that $43 \%$ of American 
children aged two months to 11 years are similarly exposed, with serum cotinine levels that are generally higher than those of adults. ${ }^{14}$ Maternal smoking is a particularly important determinant of exposure in infants and young children, ${ }^{15-17}$ and children in single-parent families may be at higher risk than children in two-parent families. ${ }^{18}$

For infants and children, the home is often the most important site for ETS exposure. Therefore, programmes and policies to counter ETS in the home are the next logical steps in a comprehensive strategy to reduce childhood morbidity and mortality caused by ETS. Survey evidence from Ontario, Canada, indicates strong support for voluntary restrictions on the exposure of children to ETS in the home. ${ }^{19-21}$ and, in 1996, almost $40 \%$ $(39.4 \%)$ of the population favoured a legal restriction. ${ }^{21}$ A majority (54.6\%) expressed support for a law prohibiting children's exposure to ETS in cars, ${ }^{21}$ which can be viewed as extensions of the home. However, the potential for change rests not only on attitudes, ${ }^{22}{ }^{23}$ but on realities of housing, income, and child care. ${ }^{24}$

\section{Social, economic, legal, and political issues}

Several factors contribute to a lower level of support for ETS control measures in homes compared with workplaces and many public settings. Some believe that government or other external agents should not interfere with behaviour in private settings. ${ }^{23}$ For many people, "my home is my castle" and the "sanctity of the home" are deeply entrenched tenets. This general belief contrasts with laws and regulations that protect children from physical and sexual abuse, and those that require attendance at school, immunisation, and infant restraint and seat belt use in vehicles. Social pressures are also involved-even parents who want to make their homes smoke-free may be reluctant to offend family members, relatives, and friends.

Some health and social welfare professionals raise additional concerns. Representatives of low-income and single-parent women's groups at a recent Health Canada conference on Women and Tobacco ${ }^{25}$ expressed strong opposition to even exploring the potential for restricting smoking in homes. They envisioned harassment of low-income mothers and feared that children might be removed from homes that were not smoke-free. Time out for smoking was viewed as one of the few breaks that such women allow themselves, and cigarettes were seen as providing some solace in an otherwise stressful and unrewarding life. The issue was perceived as feminist and "classist", with middle-class and upper-class professionals imposing their health values on low-income women. This may represent an extension of views that oppose interfering with pregnant women's use of tobacco, alcohol, and illicit drugs. ${ }^{26}$

Low-income families may encounter more real difficulty providing smoke-free environments. Low-income parents are more likely to smoke and to have friends who smoke. ${ }^{27-30}$ They are more likely to live in small housing units, usually apartments, with limited access to the outdoors, few rooms, and shared ventilation systems. They often have no balconies or garages to use for smoking outdoors. Many single parents would have to leave their children alone or bring them along every time they went outside to smoke.

Even without explicit regulation of home environments, court cases have brought the issue of ETS in the home into the legal arena. In the United States and Canada, children with asthma have been the focus of cases involving access to children and custody by smoking parents. ${ }^{23} 3132$ (Rob Cunningham, Canadian Cancer Society, written communication, 30 April 1996.) Parents who refused to provide smoke-free environments for asthmatic children have been denied access or custody. Sweda $^{33}$ reviewed 33 American child custody cases between 1989 and 1996. Most decisions favoured protection of children from ETS (24 vs 9] and the existence of respiratory illness in the child does not appear to be a factor. In some cases that involved protection from ETS, custody was granted to the non-smoking parent; in others, both parents were forbidden to smoke in the presence of the child. A few allowed smoking in other parts of the home, but most involved a complete ban, including a ban in vehicles. In some cases, the court ruled that failure to stop smoking around the child was evidence for a lack of concern for the child's wellbeing. In one case (Heck vs Reed, ND, 1995), the court reversed a decision awarding custody to a non-smoking father because the father had perpetrated domestic violence, ruling that "We do not believe that the legislature intended that the presumption against awarding custody of children to a perpetrator of domestic violence be trumped by the fact that the victim-parent smokes." A second opinion noted: "I also do not agree with the majority's trivializing the harm of cigarette smoke to an asthmatic child. . . Under N.D. C.C. secs. 14-07.1-01, domestic violence includes 'physical harm.' Smoking in the presence of an asthmatic child whose health is thereby threatened may well constitute such physical harm."

Involvement of healthcare professionals in the identification of ETS exposure, particularly for children with respiratory disease, raises issues regarding interference on the one hand and failure to act on the other. The evidence of family physicians was a critical factor in some custody cases. For example, in the case of Wilk vs Wilk (Mo. App. 1989), a non-smoking mother, who was advised by a doctor that her asthmatic child should not visit the smoking father's home, was awarded primary custody of the child. In other cases, "medical advice" was introduced as a supporting argument for the decision.

Other regulatory concerns involve the exposure of non-smoking tenants to ETS, owing to shared ventilation systems. In Fort Pierce, Florida, the local housing authority has required new tenants to sign an agreement not 
to smoke in apartments under its jurisdiction. This is thought to represent the first time residents have been banned from smoking at home by a public body. ${ }^{34}$

Despite a tradition of protection of children that is enshrined in law, if not always in practice, a chief political issue is the belief that intrusion in private environments is inappropriate. Consequently, children are afforded less protection by law from ETS exposure from their parents than from the smoking of strangers in public places. This discrepancy, may, in part, be based on the notion that parents have a greater vested interest in the wellbeing of their children and can be counted on to protect them from harm. The political will to intervene in the home, however, has been demonstrated in child abuse legislation.

\section{Programme and policy options and strategies}

Intervention options to reduce ETS exposure in the home include public education, community programmes, clinical interventions, policy and advocacy statements, legal and regulatory measures, and monitoring and evaluation mechanisms.

Education to inform the public about the adverse health effects of ETS and effective ways of controlling exposure, can take many forms, including information disseminated via electronic and print media, billboards, and even warnings on cigarette packages. Messages may need to be targeted separately, not only for adults, adolescents, and children, but according to attitudes to smoking and ETS and receptivity to information and influence. A major Canadian study commissioned by Health Canada showed that about 30\% of the parent population were somewhat or very likely to respond to messages, but had not yet converted to an anti-smoking stand ${ }^{35}$ whereas an additional $11 \%$ were considered less likely to respond to information but had potential for change. The "sceptics" (16\%) doubted sources of information and were considered a difficult target, and $7 \%$ were deemed to be highly resistant to change. Behaviour change in the latter groups may require more intensive interventions. ${ }^{36}$ In this unpublished study, it was found that $61 \%$ of parent homes surveyed reported some restrictions on smoking in the home, whereas among homes with smokers, only $43 \%$ had such restrictions. At this time, there is a paucity of data in the peer-reviewed literature on the extent and means by which smoking is restricted in Canadian homes. However, in one study of informal controls in households in Winnipeg, Canada, Goldstein ${ }^{37}$ concluded that the gap between knowledge of harmful effects $(90 \%)$ and actual controls $(24 \%)$ in the home indicates a need to look at situational factors that interfere with the adoption of rules in the home. That this gap is worth addressing is documented in recently published survey data from the state of Massachusetts indicating that the ETS exposure for adolescents living with adult smokers is substantially lower in households with smoking restrictions. ${ }^{38}$
Evaluations of community-based programmes to reduce ETS exposure in homes, reported from Ontario ${ }^{39}$ and elsewhere, ${ }^{4041}$ indicate variable success. Such programmes could provide support and direction for those who have difficulty enforcing their own preferences. Approaches that try to extend current behaviours in the workplace and public places might be more effective than those that require a new repertoire of responses. For example, smokers could be reminded that, as they do not expose their coworkers or the general public in many places, they should extend the same benefits to their children and partners. ETS awareness and control strategies for the home could also be incorporated into mandatory tobacco education programmes in schools. Demonstration projects with full evaluation components and potential for national dissemination and implementation are needed.

Efforts to upgrade the knowledge and skills of health professionals with regard to smoking per $s e^{42}$ should be reviewed to ensure that effective intervention with parents, other caregivers, and children themselves concerning ETS exposure and its control is also addressed. Many health professionals are advantageously placed to intervene with these groups, and some evidence of reduction of ETS exposures in home environments has been found in clinical studies involving parents with asthmatic children and newborn infants. ${ }^{43-47}$ Successful interventions aimed at increasing the effectiveness of family physicians ${ }^{48}$ and paediatricians ${ }^{49}$ in reducing ETS exposure are now being reported. Further, there is evidence that parents expect such advice..$^{50} 51$

Policy and advocacy statements create awareness of issues and help to set agendas for action. Recently, some voluntary health associations, expert groups, professional associations, and government agencies have enunciated public positions advocating strategies to protect children from ETS exposure. $^{52-60}$ In Canada, a recent national workshop on ETS featured exposure in the home on an equal basis with exposure in public places and workplaces. ${ }^{61}$

There may still be considerable resistance to exploring the applicability and feasibility of legal and regulatory interventions. The extent to which existing statutes and regulations could be used to address ETS control in homes is not known, although child protection legislation could be extended or interpreted to include ETS exposure, particularly for infants and children with compromised respiratory systems. As noted above, such exposure has been taken into account in determining the best interests of the child in recent court decisions in the United States and Canada concerning custody and access in divorce action. ${ }^{231-33}$ (Rob Cunningham, Canadian Cancer Society, written communication, 30 April 1996.)

Monitoring and evaluation are critical components of any strategy to reduce ETS exposure in the home, particularly because of the difficulties in measuring compliance. Systematic monitoring of the general 
population with regard to attitudes and behaviour should be carried out in surveys. Self-reported data need to be supplemented by objective monitoring systems. Evaluation components are critical if we are to learn which programmes and policies are effective in reducing ETS exposure.

\section{Research priorities}

Although it is clear that the protection of children from ETS in home environments should be a priority for programme and policy development, it is also clear that the issues are diverse and complex, and that the current research base is inadequate to fully support such development. Priority areas for research include: attitudes and intentions of health professionals and policy makers concerning ETS control in homes; evaluation of existing interventions for effectiveness; assessment of public support for regulatory changes; assessment of control options under current legislation and regulations; and the potential applicability of harm reduction strategies.

We need to assess smokers' knowledge of the range and importance of health effects of ETS exposure and their beliefs about the effectiveness of various ETS reduction measures-for example, opening windows, fans, air purifiers, and filters. Specific data are also needed on exposure in various settings with various levels of ventilation, such as apartments, smaller homes, large homes, and vehicles. Contining studies that monitor the extent to which informal controls on smoking in the home are in place and the form that these controls take should be a research priority. Furthermore, we need to establish the factors most likely to change behaviour and promote effective interventions, including those in the social and policy environments. Given our limited knowledge in some of these areas, a combination of quantitative and qualitative methods would be appropriate for exploring these research priorities. Finally, although current knowledge of the health impact of ETS exposure in children is sufficient to warrant action now, there is still much to be learned about the range and seriousness of the health effects caused by ETS exposure. It is clear that a solid research base is an essential underpinning of programme and policy initiatives to reduce risks from ETS exposure among children.

\section{Addendum}

Since this paper was accepted for publication, new state-specific information has been published from the Behavioral Risk Factor Surveillance System in the United States on the estimated exposure of children to ETS in the home in $1996 .{ }^{62} \mathrm{~A}$ third to a half of American adults who smoke had children living in their homes, and in most of these homes (ranging from $70.6 \%$ in Washington state to $95.6 \%$ in the District of Columbia), smoking was allowed in some or all areas of the home. Based on these findings, $21.9 \%$ of children under 18 years were exposed to ETS at home by their parents. This estimate does not include home exposure from non-parent smokers or exposure outside the home. However, the proportion of homes restricting smoking may have increased since 1992-93 when the information on restrictions was collected.

1 National Clearinghouse on Tobacco and Health. Federal and provincial tobacco legislation in Canada: an overview. Toronto, Ontario: National Clearinghouse on Tobacco and Health, March 1995.

2 US Department of Health and Human Services. Healthy people 2000. Midcourse review and 1995 revisions. Washington, DC: Public Health Service, 1995.

3 US Environmental Protection Agency. Respiratory health effects of passive smoking: lung cancer and other disorders. Smoking and Tobacco Control Monograph No 4. Bethesda, Maryland: US Department of Health and Human Services, Public Health Service, National Institutes of Health, 1993. (NIH Publication No 93-3605.)

4 California Environmental Protection Agency. Health effects of exposure to environmental tobacco smoke. Sacramento, California: Office of Environmental Health Hazard Assessment, 1997.

5 DiFranza JR, Lew RA. Morbidity and mortality in children associated with the use of tobacco products by other people. Pediatrics 1996; 97:560-8.

6 Stoddard JJ, Gray B. Maternal smoking and medical expenditures for childhood respiratory illness. Am f Public Health 1997;87:205-9.

7 Aligne CA, Stoddard JJ. Tobacco and children: an economic evaluation of the medical effects of parental smoking. Arch Pediatr Adolesc Med 1997;151:648-53.

8 Willers S, Skarping G, Dalene M, et al. Urinary cotinine in children and adults during and after semiexperimental exposure to environmental tobacco smoke. Arch Environ Health 1995;50:130-8.

9 Bull SB, Pederson LL, Ashley MJ. Restrictions on smoking: growth in population support between 1983 and 1991 in

10 Repace JL. Risk management of passive smoking at work and at home. Saint Louis Univ Public Health Law Rev 1994;13:763-85.

11 Löfroth G. Environmental tobacco smoke: multicomponent analysis and room-to-room distribution in homes. Tobacco Control 1993;2:222-5

12 Canada Mortgage and Housing Corporation. The clean air guide. How to identify and correct indoor air problems in your home, rev ed. Ottawa, Ontario: Canada Mortgage and Housing Corporation, 1993.

13 Health Canada. Survey on smoking in Canada. Cycle 2. Ottawa: Health Canada, 1994.

14 Pirkle JL, Flegal KM, Bernert JT, et al. Exposure of the US population to environmental tobacco smoke. $\mathcal{F} A M A$ 1996; 275:1233-40.

15 Greenberg RA, Bauman KE, Glover LH, et al. Ecology of passive smoking by young infants. F Pediatr 1989;114:774-

16 Chilmonczyk BA, Knight GJ, Palomaki GE, et al. Environmental tobacco smoke exposure during infancy. $A m \mathcal{F} P u b-$ lic Health 1990;80:1205-8.

17 Cook DG, Whincup PH, Jarvis MJ, et al. Passive exposure to tobacco smoke in children aged 5-7 years: individual, family, and community factors. BMf 1994;308:384-9.

18 Jaakkola N, Ruotsalainen R, Jaakkola JJK. What are the determinants of children's exposure to environmental tobacco smoke at home? Scand f Soc Med 1994;22:10712 .

19 Ferris J, Templeton L, Wong S. Alcohol, tobacco and marijuana: use, norms, problems, and policy attitudes among Ontario adults. A report of the Ontario Alcohol and Other Drug Opinion Survey, 1992. Addiction Research Foundation: Internal Document No 118. Toronto, Ontario, September 1994.

20 Bondy SJ, Ferrence RG. Smoking behaviour and attitudes in Ontario, 1993. A report of the 1993 Ontario Alcohol and Other Drug Opinion Survey. Ontario Tobacco Research Unit, Working Paper Series No 2, Toronto, Ontario, 1995.

21 Anglin L, ed. The Ontario experience of alcohol and tobacco: new focus on accessibility, violence, and mandatory treatment. A report of the Ontario Alcohol and Other Drug Opinion SurA report of the Ontario Alcohol and Other Drug Opinion Survey (OADOS), 1995. Addiction Research Foundation of November 1995.

22 Fish L, Wilson SR, Latini DM, et al. An education program for parents of children with asthma: differences in attendance between smoking and nonsmoking parents. $A m \mathcal{F}$ Public Health 1996;86:246-8.

23 Ezra DB. Sticks and stones can break my bones, but tobacco smoke can kill me: can we protect children from parents that smoke? Saint Louis Univ Public Health Law Rev 1994; 13:547-90.

24 Logan S, Spencer N. Smoking and other health related behaviour in a social and environmental context. Arch Dis Child 1996;74:176-9.

25 Health Canada. Women and tobacco. Second National Workshop, February 16-18, 1995. Ottawa, Ontario.

26 Blume SB. Preventing fetal alcohol syndrome: where are we now? Addiction 1996;91:473-5. 
27 Pederson LL. Smoking. In: Stephens T, Fowler GD, eds. Canada's Health Promotion Survey 1990: technical report. Health and Welfare Canada. Ottawa, Ontario: Ministry of Supply and Services Canada, 1993. (Catalogue No H39-263/2-1990E.)

28 Nelson KP, Ford RPK, Wild CJ. Women in low income groups smoke more: Canterbury, 1976-92. NZ Med f 1995; 108:148-50.

29 Kleinschmidt I, Hills M, Elliott P. Smoking behaviour can be predicted by neighbourhood deprivation measures. $\mathcal{F}$ Epidemiol Commun Health 1995;49(suppl 2):S72-7.

30 Marsh A, McKay S. Poor smokers. London: Policy Studies Institute, 1994

31 Schwartz AD. Environmental tobacco smoke and its effect on children: controlling smoking in the home. Environ Affairs 1993;20:135-171.

32 Liberman E. Custody and access: no smoking allowed! Report prepared for the Ontario Tobacco Research Unit, Univerprepared for the Ontario Tobacco Res
sity of Toronto, Ontario, April 1995.

33 Sweda EL. Summary of legal cases regarding smoking in the workplace and other places. Boston, Massachusetts: Tobacco workplace and other places. Boston, Mast

34 Anon. David huffs, Goliath puffs. Reprinted from The Economist in the Globe and Mail (Toronto, Ontario), 18 May 1996

35 Ekos Research Associates Inc. An assessment of knowledge, attitudes, and practices concerning environmental tobacco smoke. Final report. Submitted to Health Canada, March 31, 1995.

36 Abrams DB, Rohsenow DJ, Niaura RS, et al. Smoking and treatment outcome for alcoholics: effects on coping skills, urge to drink, and drinking rates. Behav Ther 1992; 23:283-297.

37 Goldstein JE. Informal smoking controls in Winnipeg households. Can 7 Public Health 1994;85:106-9.

38 Biener L, Cullen D, Di ZX, et al. Household smoking restrictions and adolescents' exposure to environmental tobacco smoke. Prev Med 1997;26:358-63.

39 Bondy SJ, Connop H, Pope M, et al. Promoting smoke free families. Report of a pilot intervention trial to reduce
environmental tobacco smoke in family homes. Ontario environmental tobacco smoke in family homes. Ontario Toronto, Ontario, 1995.

40 Vineis P, Ronco G, Ciccone G, et al. Prevention of exposure of young children to parental tobacco smoke: effectiveness of an educational program. Tumori 1993;79:183-6.

41 Greenberg RA, Strecher VJ, Bauman KE, et al. Evaluation of a home-based intervention program to reduce infant passive smoking and lower respiratory illness. F Behav Med 1994; 17:273-90

42 Canadian Council on Smoking and Health. Guide your patients to a smoke free future. Ottawa, Ontario: Canadian Council on Smoking and Health, 1992 .

43 Murray AB, Morrison BJ. The decrease in severity of asthma in children of parents who smoke since the parents have been exposing them to less cigarette smoke. $\mathcal{F}$ Allergy Clin Immunol 1993;91:102-10.

44 McIntosh NA, Clark NM, Howatt WF. Reducing tobacco smoke in the environment of the child with asthma: a smoke in the environment of the child with asthma: a cotinine-assisted,

45 Hovell MF, Meltzer SB, Zakarian JM, et al. Reduction of environmental tobacco smoke exposure among asthmatic children: a controlled trial. Chest 1994;106:440-6.
46 Wall MA, Severson HH, Andrews JA, et al. Pediatric officebased smoking intervention: impact on maternal smoking and relapse. Pediatrics 1995;96:622-8.

47 Winkelstein ML, Tarzian A, Wood RA. Parental smoking behaviour and passive smoke exposure in children with asthma. Ann Allergy Asthma Immunol 1997;78:419-23.

48 Narce-Valente S, Kligman EW. Increasing physician screening and counseling for passive smoking. F Fam Pract 1992; 34:722-8.

49 Kosower E, Ernst A, Taub B, et al. Tobacco prevention education in a pediatric residency program. Arch Pediatr Adolesc Med 1995;149:430-5.

50 Frankowski BL, Weaver SO, Secker-Walker RH. Advising parents to stop smoking: pediatricians' and parents' parents to stop smoking: pediatriciar
attitudes. Pediatrics 1993;91:296-300.

51 Klein JD, Portilla M, Goldstein A. Training pediatric residents to prevent tobacco use. Pediatrics 1995;96:32630.

52 American Heart Association. Active and passive tobacco exposure: a serious pediatric health problem. A statement from the Committee on Atherosclerosis and Hypertension in Children, Council on Cardiovascular Disease in the Young. Circulation 1994;90:2581-90.

53 Canadian Task Force on the Periodic Health Examination. Canadian guide to clinical preventive health care. Ottawa, Ontario: Health Canada, 1994.

54 American Academy of Pediatrics. Committee on Substance Abuse. Tobacco-free environment: an imperative for the Abuse. Tobacco-free environment: an imperative for the
health of children and adolescents. Pediatrics 1994;93:8668 .

55 Ontario Task Force on the Primary Prevention of Cancer. Recommendations for the primary prevention of cancer. Toronto, Ontario: Ministry of Health, March 1995.

56 National Clearinghouse on Tobacco and Health. Preventing smoking: tobacco control policies. Toronto, Ontario: National Clearinghouse on Tobacco and Health, July 1995.

57 National Health and Medical Research Council. The health effects of passive smoking: the draft report of the NHMRC Working Party. Canberra, ACT: NHMRC, 1995.

58 US Preventive Services Task Force. Guide to preventive clinical services, 2nd ed. Chapter 54: Counseling to prevent tobacco use. Baltimore, Maryland: Williams \& Wilkins, 1996.

59 Ontario Medical Association. Second hand smoke and indoor air quality. Toronto, Ontario: Ontario Medical Association, 1996.

60 American Academy of Pediatrics. Committee on Environmental Health. Environmental tobacco smoke: a health hazard to children. Pediatrics 1997;99:639-42.

61 Ashley MJ, Ferrence R. Environmental tobacco smoke (ETS) in home environments. A discussion paper prepared for Health Canada's Strategic Planning Workshop to Reduce ETS Exposure, October 19-20, 1995. Ottawa, Ontario: Ministry of Supply and Services Canada, 1996.

62 US Centers for Disease Control and Prevention. Statespecific prevalence of cigarette smoking among adults, and children's and adolescent's exposure to environmental tobacco smoke-United States, 1996. MMWR 1997; 46:1038-43. 